\title{
EL FACSIMIL SALMANTINO DE 1999
}

\author{
Alan Deyermond \\ Queen Mary, University of London
}

[El primer día del gran congreso ambulante de 1999 (lunes, 27 de septiembre) terminó con la presentación del facsímil, realizado por Emilio de Miguel Martínez, de la presunta editio princeps de la Comedia de Calisto y Melibea. En los cuatro años de investigación y publicación intensivas que siguieron años que culminaron en el simposio internacional de Bloomington, debido a la iniciativa de Juan Carlos Conde- la primacía cronológica de dicha edición se ha puesto en duda (por ejemplo, por GuillermoSerés en Lobera et al. 2000: 1xxiv, por Jaime Moll en 2000 y por Víctor Infantes 2002). No obstante, esta edición, independientemente de si es la princeps o, como sostiene Infantes, la última existente de la Comedia, es la primera edición ilustrada de la obra. Sus diecisiete grabados (dieciséis distintos y uno repetido) y sus iniciales decoradas constituyen el comienzo de la rica y compleja tradición de la iconografía celestinesca.

Otro cambio no previsto en el septiembre de 1999 fue el reajuste del equipo que preparaba la edición crítica para Biblioteca Clásica. En dicho reajuste, que se realizó en circunstancias todavía no muy claras, Patrizia Botta salió del equipo y Guillermo Serés entró en él: compárese la portada de la edición (Lobera et al. 2000) con la del folleto publicitario distribuido en el congreso de la Asociación Hispánica de Literatura Medieval (Botta et el. 1999).

Emilio de Miguel Martínez me honró con la invitación a participar en la presentación de su facsímil. Recientemente descubrí el texto de mi intervención, que creía perdido. La transcribo aquí, esperando que tenga cierto interés histórico. Tiene sólo una modificación: a la luz de lo que me informó Patrizia Botta después de la presentación, omito el pasaje que comentó una nota del folleto publicitaria.]

Este facsímil, sobre todo en su versión de lujo, reproduce casi exactamente la forma externa de la editio princeps. Nunca sabremos cómo fue oír por primera vez una lectura pública de la Comedia de Calisto y Melibea ('quando diez personas se juntaren para oýr esta comedia', según el prólogo a la 
Tragicomedia; Alonso de Proaza 'Dize el modo que se ha de tener leyendo esta comedia'). Ahora, sin embargo, podemos saber cómo fue tomar la Comedia de 1499 cuando salió de la imprenta de Fadrique de Basilea -tomarla, abrirla y leerla.

Recuerdo pasar por la Hispanic Society of America hace casi treinta años, cuando Clara Louisa Penney, entonces bibliotecaria, puso en mis manos el ejemplar único de esta edición. Fue un momento inolvidable, y siempre recuerdo con agradecimiento a la doctora Penney (hace años que en paz descansa), no sólo por aquel momento sino por su trabajo fundamental, The Book Called 'Celestina' in the Library of the Hispanic Society of America (1954), y por ser una -sospecho que la principal- de las responsables por 'el magnífico estado de conservación del ejemplar' (Miguel Martínez 1999: 15). Pero incluso a la doctora Penney no le era posible conseguir para este precioso ejemplar una encuadernación parecida a los originales de la época, como la que tengo esta noche en mis manos ('en mis braços te tengo y no lo creo', como dijo Calisto).

Este facsímil y el estudio preliminar se hicieron en presencia del original, y después de un estudio detenido del mismo. Es notorio que muchos investigadores -y no pocos de los que han publicado ediciones de la Celestina-se han apoyado únicamente en el facsímil realizado en 1909 por Archer M. Huntington y dos veces reimpreso, o, si han visto el original, lo han hojeado durante pocos minutos. Huelga decir que incluso un facsímil cuidado, como el de Huntington (a diferencia de muchos de la primera mitad del siglo XX, que son facticios y/o retocados), no sustituye adecuadamente el original. Para los bibliófilos, sí, pero no para los investigadores, porque un facsímil difícilmente puede reproducir las exactas condiciones físicas del original (marginalia, filigranas, estructura de los cuadernos). Por eso la importancia de la admirable seriedad con la cual Emilio de Miguel se ha apoyado en un escrutinio del original.

La edición que acompaña el facsímil se llama modestamente 'transcripción', pero no lo es. Es verdad que no es estrictamente una edición crítica (como dice el editor, 1999: 30), pero es mucho más que transcripción. Es una edición no sólo corregida sino también enmendada a la luz de otras ediciones de la Comedia (e incluso, aunque raras veces, de la Tragicomedia). Y es, con criterios muy sanos, regularizada pero no modernizada. Es interesante, además, tener en la mesa la excelente edición crítica de Jerry Rank (1978), basada en la edición de Sevilla 1501. De este modo, comparando las lecturas de Rank con las notas textuales de Miguel Martínez (1999: 385-394), podemos formarnos una idea de cómo fue la historia de la Comedia.

Por si fuera poco, cada página de la edición tiene en frente su versión modernizada. Se trata de una modernización conservadora: la ortografía es la moderna, y cuando el original tiene una palabra anticuada (incluso cuando esté todavía en el diccionario, como 'aína') se sustituye, pero casi siempre se conserva 
la sintaxis del original, sustituyéndola sólo cuando hay peligro de incomprensión ('Entre comer' es sustituido por 'Pónense a comer'). El resultado es un texto moderno que servirá a dos clases de lectores: los que no saben nada del castellano bajomedieval, pero que quieren leer una versión lo más acercada posible al original, y los que saben algo del castellano medieval pero no lo dominan totalmente, y que por lo tanto necesitan ayuda de vez en cuando al leer el texto original.

El estudio preliminar es muy útil, muy interesante. Versa principalmente sobre la tradición impresa de la Comedia (por eso, no dice casi nada de la Tragicomedia, que desde luego es posterior, ni nada del manuscrito de Palacio, que si no es anterior a las ediciones existentes -muy posible, como nos recordó Francisco Lobera hace unas horas-, es algo aparte).

El tomo complementario, pues, constituye una aportación valiosa a los estudios celestinescos y al conocimiento de la Comedia. Felicito y agradezco a Emilio de Miguel Martínez y a la editorial esta magnífica e imprescindible publicación.

\section{OBRAS CITADAS}

BOTTA, Patrizia, et al., ed., 1999. Fernando de Rojas (y antiguo autor), La Celestina: Tragicomedia de Calisto y Melibea, ed. Patrizia Botta, Paloma DíazMas, Francisco J. Lobera, Carlos Mota, \& Íñigo Ruiz Arzálluz. Folleto extraído de la primera e inédita versión de Biblioteca Clásica, 20 (Barcelona: Crítica).

HUNTINGTON, Archer M., ed., 1909. Celestina 1499 (New York: Hispanic Society of America). Reprinted 1970 and 1995.

INFANTES, Víctor, 2002. 'El laberinto cronológico y editorial de las primitivas ediciones de Celestina (1497-1514)', ponencia leída en en simposio,1502-2002: Five Hundred Years of Fernando de Rojas' Tragicomedia de Calisto y Melibea (Indiana University, 18-19 de octubre).

LOBERA, Francisco J., et al., ed., 2000. Fernando de Rojas (y 'antiguo autor'), La Celestina: Tragicomedia de Calisto y Melibea, ed. Francisco J. Lobera, Guillermo Serés, Paloma Díaz-Mas, Carlos Mota, Íñigo Ruiz Arzálluz, \& Francisco Rico, Biblioteca Clásica, 20 (Barcelona: Crítica).

MIGUEL MARTÍNEZ, Emilio de, ed., 1999. Fernando de Rojas, 'Comedia de Calisto y Melibea', Burgos, 1499, Tesoro Bibliográfico, 15, 2 vols (Salamanca: Ediciones Universidad de Salamanca, Junta de Castilla y León, \& Caja Duero). MOLL, Jaime, 2000. "Breves consideraciones heterodoxas sobre las primeras ediciones de La Celestina”, Voz y Letra, Revista de Filología 11.1, pp. 21-25.

PENNEY, Clara Louisa, 1954. The Book Called 'Celestina' in the Library of the Hispanic Society of America (New York: HSA, vii +157 pp.).

RANK, Jerry R., ed., 1978. Fernando de Rojas, Comedia de Calisto y Melibea, Estudios de Hispanófila, 49 (Chapel Hill, NC: Estudios de Hispanófila). 


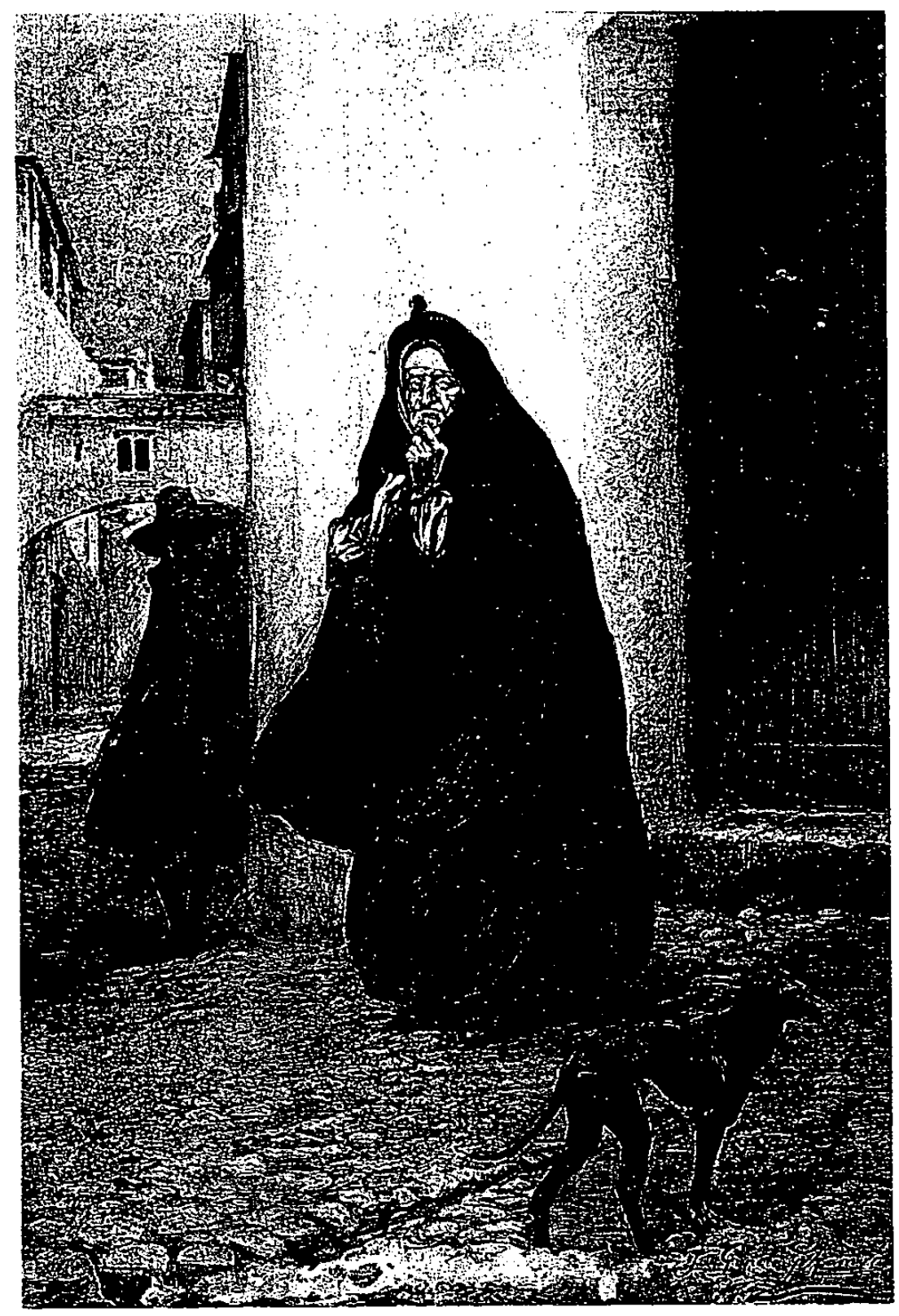

Una vieja . José García Ramos

Último tercio del s. XIX

Real Acad. Sevillana de Buenas Letras 